\title{
O MENINO DE AREIA: UM ROMANGE ARABE ESCRITO EM FRANCES (ou os labirintos da escritura)
}

\author{
Edson Rosa da Silva \\ Universidade Federal do Rio de Janeiro
}

RESUMO

\begin{abstract}
Análise da escritura do escritor marroquino Tahar Ben Jelloun como um texto dinámico em constante enunciação. A supremacia do significante. A escritura como risco que exige o abandonar-se aos segredos e aos sentidos imprevisiveis das palavras. $O$ jogo intra/intertextual na estru. tura do romance. As mil e uma versōes de uma estória inacabada.
\end{abstract}

Estranha situaçāo! Dir-se-ia que eu figurava no interior de um livro, que eu era um desses personagens pitorescos que surgem no meio de uma narra. tiva para inquietar o leitor. Talvez fosse um livro entre os milhares apinhados naquela biblioteca onde, em outros tempos, eu vinha trabalhar. $\mathbf{E}$, ao menos, tal como o concebo, um livro é um labirinto deliberadamente construído para confundir os homens, com a intenção de fazer com que se extraviem ou regressem às dimensões estreitas de suas ambições.

(O menino de areia, p. 173) ${ }^{1}$

Labyrinthos, palavra grega que significa originalmente o palácio cretense de Minos, remete, etimologicamente, à palavra lábrys, que significa, por sua vez, machado, e adquire também o sentido de palácio dos machados, em razão do duplo machado que se acha gravado em inúmeros monumen. tos minoenses (cf. CHEVALIER \& GHEERBRANT, Le

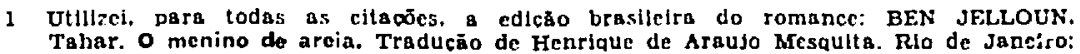
Nova Frontelra, 1986. 
dictionnaire des symboles). Por outro lado, o mito de Teseu e o Minotauro reforça a idéia de morte contida nesse instrumento de guerra com a idéia de ameaça, de prisão, de dificuldade e de confusão, aliada, no entanto, à iđéia de solução advinda de um fio (lembremos o verbo latino resolvëre, ação advinda de um fio (lembremos o verbo latino solvere, ação de desatar), fio que se desata, se desenrola e conduz à saida.

Ora, conceber um livro como um labirinto não é de for. ma alguma uma proposta inocente ou insignificante, sobretudo porque a sequiència da definição confirma as conotaçōes de perigo que acabo de lembrar: "um livro (...) é um labirinto deliberadamente construido para confundir os homens, com a intenção de fazer com que se extraviem ou regressem às dimensōes estreitas de suas ambiçōes". Deleitando-me, ainda, com o jogo das significaçōes do texto, diria que a palavra confundir (do latim confundere) não possui unicamente o sentido moderno de deixar estupefato, desconcertar, mas também o de destruir, aniquilar, e, até mesmo, em latim, o de lutar. E, se a função do fio se reveste de um caráter positivo no mito de Teseu, o fio do labirinto narrativo reforça a idéia de prisão, de uma prisão que se reduz às "dimensōes estreitas (das) ambições dos homens".

Eis ai, portanto, explicitamente colocadas, as intençōes do texto. Escrever impõe riscos, escrever exige uma iniciação pessoal e um abandono aos segredos das palavras que vão e vêm, à deriva, que se esvaziam de sentido e que adquirem outros, que não oferecem nenhuma garantia, ao contrário, destróem toda certeza e toda verdade. Para citar Maurice BLANCHOT,

escrever exige o abandono de todos (os) principios, ou seja o fim (...) de tudo o que garante nossa cultura, não para voltar idilicamente para trás, antes porém para ir além, quer dizer, até o limite, a fim de tentar romper o circulo, o circulo de todos os círculos?

Se $o$ ato de escrever é um engajamento temivel, $o$ ato de ler não é menos perigoso, pois o leitor acha-se também "entremeado pelos fios de lã de uma mesma história" (p. 29), tornando-se, assim, parte integrante do romance, submetido, ele, leitor, ao "rosto do sol imóvel" e ao "rosto da lua assassina" (p. 27). Se o ato de escrever não é um ato sem riscos, mais arriscado ainda é $o$ ato de um escritor árabe que se

2 BLANCOT. Maurice, L'entretien infini. Paris: Gallimatd, 1969. D. VII. 
expressa em francês, enfrentando o conflito da identidade cultural diante da língua da colonização.

$$
\therefore \approx
$$

O texto em cujo labirinto quero fazer o leitor penetrar é $O$ menino de areia de Tahar BEN JELLOUN, escritor marroquino, poeta e romancista, autor de vários livros, ganhador do prêmio goncourt de 1987, com o romance, ainda não traduzido entre nós, La nuit sacrée.

A história de $\mathbf{O}$ menino de areia é a história de Ahmed, oitava filha de uma familia árabe, cujo pai, contornando a determinação do destino, decide "torná-la" menino perante a sociedade, a fim de recuperar a honra, e porque "a religião trata sem piedade o homem sem herdeiro" e "de tudo ela o despoja, ou de quase tudo, em favor dos irmãos" (p. 18). Sem dúvida alguma, um tema exótico, comovente e sedutor, que nos abre as portas do mundo árabe e de seus problemas. Do ponto de vista de uma análise da sociedade marroquina, a narrativa fornece inumeros elementos que permitiriam estudar certos aspectos da realidade do país, tais como a condição feminina nos paises árabes. Aliás, a obra de Tahar BEN JELLOUN nos faz sempre refletir sobre as questões sociais de seu povo, como aquela a que me referi acima: o problema da identidade cultural árabe versus a expressão francesa. La réclusion solitaire (1976) e Moha le fou, Moha le sage (1978) tratam desse tema: no primeiro, temos a história de um trabalhador imigrante que vive na França como um exilado, na solidão e na lembrança de suas origens; no outro, são os conflitos do homem que vê a própria terra colonizada e dominada por uma cultura estrangeira. Moha é a voz que fala pelos oprimidos e pelos vencidos. Fala, por vezes, de forma desordenada, absurda, excessiva, desmascarando a forma correta e cartesiana do discurso do poder. Há, nesses romances em que os limites entre a poesia e a narrativa não se deixam efetivamente precisar, uma reflexāo importante sobre o poder das palavras, "palavras perigosas (...), quando pro. vêm de um abismo, de debaixo da terra, de detrás das pedras e das muralhas"3.

Ao lado, entretanto, de uma abordagem social possivel do referente árabe, importa perguntar como os elementos do real são mediatizados no texto, e discutir a autonomia do textual em relação à realidade que o romance trabalha esteticamente e com a qual compõe um tecido artístico. A importância do tema da conđição da mulher árabe aqui não está simplesmente na retomada de uma questão atual e polêmica.

3 BEN JELLOUN, Tahar. Moha le fou, Moha to sage. Parls: Beull, 1978. D. 132. 
Isso seria evidente demais. A importância estaria, talvez, na assimilaçăo do problema pela estrutura do texto: o concerto de vozes amordaçadas que se reúnem pela escritura, que se fazem ouvir na Fragmentação da história de Ahmed, dita, redita, contada e recontada por inúmeros narradores, afirmada, confirmada, recusada, contornada, recomeçada pela intromissão de mil vozes descontentes com o desenrolar dos acontecimentos narrados e que os interrompem ou transformam para reordená-los. Ao invés de descrever o conflito social, o romance lhe dá um estatuto textual e, puxando os fios de um lado e de outro, nos ensina a tecer: "De mim até vós, de cada um de vós até mim, diz um dos contadores, partem fios. Ainda são frágeis. Ligam-nos, no entanto, como um pacto" (p. 29). Tornando-nos cúmplices da história, fazendo de nós colaboradores ou operários do texto, o contador nos faz sentar ao lado dos seus ouvintes na praça pública, ao lado daquele povo que avidamente seguia o relato das aventuras de Ahmed que se libertou da Lei imposta pelo Pai - a ordem dominante em sua casa - e reescreveu seu destino. A lição do contador da praça é a mesma lição do escritor que quer fazer a história das minorias abandonadas, maltratadas, esquecidas, sem vez e sem voz. Sem direito a uma história própria, colocados à força dentro da história dos outros.

A relação contador/ouvinte - que permite a cada um contar a sua versão da história de Ahmed - restabelece uma relação de liberdade que se realiza definitivamente através da composição do texto. No momento em que está narrando o periodo da adolescência do personagem, um dos contadores diz ao povo o seguinte:

Ora, trata-se de um periodo muito obscuro (...) que devemos imaginar e, se estais prontos a seguirme, pedir-vos-ei ajuda para reconstituir esse espaço em nossa história. No livro, nāo é mais que um espaço em branco, páginas nuas, deixadas em suspenso, oferecidas à liberdade do leitor. Cabe, portanto, a vós falar... (p. 41).

E a reaçāo da platéia é interessante. Cada um dá a sua interpretação da história, como que a mostrar que a verdade não pode ser única e que todos têm o direito de falar.

Um diz:

Penso que é o momento em que Ahmed toma consciência do que com ele se passa, e que atravessa uma crise profunda. Imagino-o dilacerado entre a evolução do seu corpo e a vontade do pai de transformá-lo de qualquer maneira num homem... 
Um outro contesta: "Quanto a mim, não creio nessa história de crise. Parece-me que Ahmed foi fabricado e que se desenvolve segundo a estratégia do pai". A que um outro replica:

Não! o que se passou é simples. Eu sei. Sou o mais velho do público, talvez mais velho ainda do que o nosso venerado mestre e narrador, que saúdo respeitosamente. Conheço essa história. Não tenho necessidade de adivinhar ou de fornecer explicaçōes... Ahmed nunca deixava o pai. Foi fora de casa e longe das mulheres que fez a sua educação.

Um outro diz ainda: "Isso pouco nos faz progredir, caro decano! Digo-te isto porque nossa história não sai do lugar. Será que somos capazes de inventá-la? Poderiamos dispensar o livro?" O último toma a palavra: "Se o permitirdes, eu vos direi a verdade: é uma história de loucura! Se Ahmed realmente existiu, deve estar internado num asilo de alienados..." E, dirigindo-se ao contador, conclui: "Como dizes contar com a prova no livro que escondes, por que não o dar a nós... Veremos entāo se essa história correspondente à verdade, ou se tudo inventaste para abusar de nosso tempo e de nossa paciência!..." Ao que o contador finalmente responde:

E o vento da rebelião que se levanta! Sois livres para acreditar ou não acreditar nesta história. Ao vos associar a esta narrativa, o que eu tinha na cabeça era avaliar vosso interesse... Vou ler a continuação. . Ela é impressionante. Abro o livro, passo pelas páginas em branco... Escutai! (p. 43).

Muito modernamente, esses textos suscitam o debate sobre o papel da recepção - o leitor/ouvinte - na criação romanesca. Mais que isso: suscitam a questão e realizam o debate.

O livro a que se refere o contador é um diário que se acreditava escrito pela mão de Ahmed e que continha seus segredos: "Ali se encontra o segredo, naquelas páginas, tecido por sílabas e imagens. Ele o havia confiado a mim pouco antes de morrer" (p. 12). O caderno de Ahmed, é, em suma, a escritura da violência sofrida por seu corpo, e da aventura do corpo violado que se liberta da lei paterna. A introdução desse caderno na narrativa de Ben Jelloun é a textualização do discurso das minorias, a inscrição definitiva dos prantos e lamentos daqueles que foram calados pela palavra da ordem. A multi-fragmentação das vozes narrativas - que se opōem e 
completam - é a assimilação pela estrutura romanesca do feed-back dos leitores que convocam as diferenças em detrimento da univocidade.

O caderno de Ahmed tem o poder e o perigo da escritura: o poder imenso da pluralidade do um e o perigo sem medidas da liberdade. Por um lado, o caderno se vê multiplicar em mil versões, mil cadernos, mil contadores que ocupam as praças e reinventam as histórias do primeiro manuscrito. Por outro, o caderno não pode mais interromper o fluxo da escritura, a força pletórica da liberdade. Pois no texto inscrevem-se as diferenças culturais $\mathrm{e}$ as liberdades individuais. Nesse sentido, toda escritura é politicamente sedenta de liberdade, já que ela a todos pertence. Opõe-se à palavra do poder que, detentor da verdade de sua palavra, nāo nos permite dela nos apoderar e deformá-la, para, depois de tê-la devorado, reformá-la.

Amigos do Bem, sabei que estamos reunidos pelo segredo do verbo numa rua circular, talvez no convés de um navio e para uma travessia cujo itinerário desconheço. (p. 15).

o segredo do verbo é o que, conforme a etimologia (secretus), separa, distancia, cria um espaço marginal, essa rua circular. Uma verdade que separa é revelada pelo texto do caderno. Os que querem conhecê-la afastam-se, reúnem-se para uma travessia, para uma iniciação. Somos convidados a fazer essa viagem, somos convidados a passar as sete portas da rua que conduz ao segredo.

Retomamos, assim, a idéia do labirinto, a idéia da iniciação, de um percurso difícil, difícil de se fazer e de se compreender, o percurso da escritura-leitura, o percurso do Menino de areia, de um romance que prossegue e persegue seu próprio caminho, à procura de seu fio, de sua imagem. texto, de sua imagem tecida pelo entrelaçamento das histórias, das histórias que confundem suas palavras e imagens, que misturam as palavras e a natureza, que fundem texto e realidade. Livro aberto na natureza, narrativa exposta ao vento que lhe vira as páginas e "desperta, uma a uma, as silabas; frases ou versículos se elevam para dissipar a neblina da espera" (p. 193). O contador diz ainda: "Amo este vento que nos envolve e afasta de nossos olhos o sono. Ele altera a ordem do texto e faz com que fujam os insetos colados às páginas engorduradas". E continua: 
Vejo uma mariposa escapar das palavras manuscritas. Ela transporta algumas imagens inúteis. Vejo uma andorinha que tenta desvencilhar-se de um magma de palavras untadas de óleo raro. (...) Ouço o murmúrio da água; trata-se, talvez, de um regato que abriu caminho nas páginas do livro; ele atravessa os capítulos; a água não apaga todas as frases; será a tinta que resiste ou a água que escolhe onde passar? curioso! (p. 104).

O texto não copia o referente, não procura reproduzir a natureza e o mundo. Vai muito mais longe. Reúne as palavras e as coisas que não mais se assemelham, que não têm mais relação metafórica, mas que coabitam na mesma página, lado a lado, metonimicamente. Como diz Michel FOUCAULT:

a magia que permitia o deciframento do mundo pela descoberta das semelhanças secretas, que se escondem sob os signos, não serve mais a não ser para explicar, de modo delirante, por que as analogias decepcionam sempret.

As palavras e as coisas, o sintagma de Foucauld, concretizam-se na página do contador de Ben Jelloun. $O$ capitulo intitula-se, significativamente, "O narrador devorado por suas frases", onde a metáfora da antropofagia torna-se evidente, sobretudo se colocarmos, ao lado do "narrador devorado por suas frases", o narrador que devora suas frases e outras frases.

O fio da escritura conduz para além do mundo da analogia das coisas, conduz à origem dos signos, à separação do significante e do significado, à ausência fecunda de significação e, ainda, à produção de outros sentidos a partir de sentidos destruidos ou devorados.

Este texto que convoca a língua e o real, convoca igualmente outros textos, que vêm compor a trança do romance. Nessa viagem intertextual, sinto-me particularmente seduzido pelo "trovador cego" do capitulo 17 , que vem de longe, de um outro século, um inventor de histórias, que "passava com facilidade de uma história a outra, sem nunca (se) preocupar com a realidade" (p. 168). Esse contador é um falsificador, como ele mesmo diz, o biógrafo do erro e da mentira, esse talvez Pierre Menard, autor do Quixote, esse jogador de textos que institui o logro, jogo mentiroso em que o diverso e o mesmo se parecem, em que o discurso de um é o discurso do outro, e, no entanto, sāo diferentes.

4 FOUCAULT, Michel. Les mot ot les choses. Paris: Gallimard, 1968. p. 62. 
O trovador cego evoca, invoca e convoca aqui a figura de Borges, já visivelmente oculta nos meandros do livrolabirinto, do livro-Babel, do livro de Babel, da biblioteca borgiana onde buscamos a origem da biblioteca e do tempo. Os reflexos borgianos no texto de Ben Jelloun são fragmentários, silhuetas e sombras, realidade não copiada, forma recriada, a evocação de Buenos Aires, lembranças, e, sobretudo, essa modernidade, "esse poder infinito de reverberaçāo, essa mul. tiplicação cintilante e ilimitada", para retomar as palavras de Maurice BLANCHOT sobre Borges em Le Livre à venir".

Esse texto de um Borges revisitado traz até nós as Mil e uma noites, presença invisivel, loucamente diluída no desejo insaciável de textos, de discurso narrativo, no desejo de contar, de recontar o mesmo conto, o outro tornado mesmo e o mesmo tornado outro, os contos tornados vida e a vida tornada conto. Vida maldita, aquela que quis contar a história terrivel de Ahmed. Presa na armadilha da palavra, vida ameaçada pela morte, pois "(ousou) contar a história e o destino do oitavo nascimento" (p. 198). A história nāo pára, deve continuar, mil e um contadores, mil e uma noites, na mais pura tradiçāo árabe, mas inversamente, não para fazer viver como na história de Xerazada, antes para fazer morrer.

Um dos contadores relata, no último capítulo do romance, os problemas que teve por causa da história de Ahmed:

Não foi somente porque nos expulsaram que me apartei desta praça; no que me diz respeito, eu o fiz porque a morte liquidava um a um os meus heróis. Parti de noite, no meio da narrativa, prometendo para o dia seguinte, ao meu público fiel, o prosseguimento das aventuras. Quando regressei, já terminara a história. A morte, a noite inteira, se encarniçara sobre os principais personagens. Vi-me assim com fragmentos de história impedido de viver e de circular. (...) Tentei justificar os brutais desaparecimentos. $O$ público nāo aceitava minhas explicaçōes. De longe, a morte, cujos risos e sarcasmos eu ouvia, me ridicularizava. Eu caducava. Eu gaguejava. Já não era mais um narrador, mas um charlatão, uma marionete nas mãos da morte. De início, não compreendi o que se passava comigo. Acusei a minha memória gasta pela idade. Não se tratava sequer de uma questão de esterili-

5 Blanchot. Maurice. Le livre à venir. Paris: Gallimard. 1971. p. 141. 
dade, porque eu possuia uma grande reserva de história. Bastava começar a controlá-las para que perdessem a substância. Passei noites sem dormir. Foi durante uma de tais noites que a morte me apareceu, com os traços de um personagem, o oitavo nascimento, Ahmed ou Zahra, e ameaçou-me com todos os recursos do céu. Acusava-me de haver traido o segredo, de ter maculado, com a minha presença, o Império do Segredo onde o Segredo é profundo e oculto. Habitava-me Es-ser El Mekhfi, o supremo Segredo. Estava tão profundamente entranhado em mim que me manipulava, a despeito de minha vontade. Que importancia! Que insensatez! Já começara a minha desgraça. Era imensa a minha infelicidade, Via aproximar-se a loucura. Não contava mais com rosto que mostrasse ao público. Sentia vergonha. Sobre mim recaíra a maldição. Nem vós nem eu jamais saberemos o fim da história que não pôde atravessar todas as partes. (p. 198-9).

Que importa? Será que toda história tem um fim? Será que as mil e uma noites têm um fim? Se a história contada pode levar à loucura e à morte, a morte da história não cọntada é ainda mais trágica, pois seria o fim do desejo de aprender e de contar, pois o que conta é o contar, pois a história que se conta é uma reescritura do mundo.

Uma história é uma casa, uma casa velha, com níveis, andares, quartos, corredores, portas e janelas, despensas, adegas ou grutas, espaços inúteis. As paredes constituem a memória. Arranhai um pouco uma pedra, prestai atenção e ouvireis muita coisa! O tempo recolhe aquilo que o dia carrega $\mathrm{e}$ aquilo que a noite dispersa. Guarda e retém. A pedra é testemunha. A condição da pedra. Cada pedra é uma página escrita, lida e emendada. Tudo se conserva nas sementes da terra. Uma história. Uma casa. Um livro. Um deserto. Uma errância. (p. 202).

Condenados à errância pela história sem fim, prosseguimos nossa aventura na história, na casa, no labirinto da velha casa.

O menino de areia fecha-se com o enigma de Ahmed não resolvido. O jogo, porém, não está terminado. O labirinto continua lá, ameaçador. Pođemos nos permitir perder-nos, mais uma vez, em suas idas e vindas. Devemos, aliás, no-lo 
permitir. Não para encontrar o fio definitivo da história, mas para confundir todos os fios provisórios, para nos lançar no jogo perigoso do texto, em um corpo-a-corpo de prazer, no prazer doloroso do texto, sem soluções, pois "um livro é um labirinto deliberadamente construído para confundir os homens, com a intenção de fazer com que se extraviem ou regressem às dimensões estreitas de suas ambiçōes".

\section{REFERENCIAS BIBLIOGRAFICAS}

1 BEN JELIOUN, Tahar. La nuit sacrée. Paris: Seuil, 1987.

2 . O menino de areia. Rio de Janeiro: Nova Fronteira, 1986.

3 - Moha le fou, Moha le sage. Paris: Seuil, 1978.

4 BLANCHOT, Maurice. L'entretien infini. Paris; Gallimard, 1969.

5 Le livre à venir. Paris: Gallimard, 1971.

6 BORGES, Jorge Luis. Ficções. Porto Alegre/Rio de Janeiro, 1986.

7 FOUCAULT, Michel. Les mots et les choses. Paris: Gallimard, 1966. 